\title{
Analysis of Damaged Silicon Rubber Hose
}

\author{
Mosammad Shamsun Nahar*, Jing Zhang \\ Department of Environmental Biology and Chemistry, Graduate School of Science and Engineering, \\ University of Toyama, Toyama, Japan \\ E-mail: msnahar@sci.u-toyama.ac.jp
}

Received February 23, 2011; revised March 27, 2011; accepted April 15, 2011

\begin{abstract}
Recently, there have been many reports of silicon rubber (SR) hoses becoming brittle in juice factory within one month of purchase. The damage is a new phenomenon, and its cause is unknown. We have collected the damaged hoses attached to UHT sterilizer (ultra-high-temperature) in juice factory and examined them for chemical changes. In addition, we have analyzed the hose-washing chemicals $\left(\mathrm{NaOH}\right.$ and $\left.\mathrm{HNO}_{3}\right)$ that used in juice factory and investigated the effect of $\mathrm{NaOH}$ and $\mathrm{HNO}_{3}$ on a new hose surface in an attempt to establish a probable chemical chain reaction that could attack of the Si-O-Si backbone and cause such degradation. According to WDXRF (Wavelength Dispersive X-Ray Fluorescence), CHNS (Carbon Hydrogen Nitrogen and Sulfur) elemental analysis and FE-SEM photo mapping (Field Emission Scanning Electron Microscope) results, the amount of silicon ( $\mathrm{Si}$ ) and the oxygen $(\mathrm{O})$ concentration were much lower in the damaged hoses than in new SR hose ones. These findings reveal that oxygen-containing silicon-based backbone may leach out from the hose by washing chemicals. As a result, the hoses became brittle after one month of use in juice factory. EDS (Energy-Dispersive-Spectroscopy) peak shows that low concentration of sodium was inserted into the damaged hose surface, due to hose cleaning by $\mathrm{NaOH}$. UV-Vis Spectrometer was used to detect the Si from hose washing chemicals. It was found that the elemental composition of the damaged SR hose changed significantly and both the $\mathrm{pH}$ of washing chemicals $\left(\mathrm{NaOH}\right.$ and $\left.\mathrm{HNO}_{3}\right)$ and the exposure UTH temperature have direct effect on the brittleness of the silicon hose in juice factory.
\end{abstract}

Keywords: Atomic Concentration; Silicone Rubber; FE-SEM/EDS; Damage Mechanism; Hose Washing Chemicals

\section{Introduction}

The chemical degradation on the surface of the silicon rubbers (SR) hoses after exposure one month to the chemicals environment was determined by evaluating the damage mechanism of the SR back bone structure. SR hose have great industrial importance because of their outstanding thermostability. Silicon rubbers is a rubberlike material composed of silicone, itself a polymer, containing silicon together with carbon, hydrogen, and oxygen. SR is neither organic nor inorganic. It is classified as an organo-silicon compound. This is due to the very important bond between carbon (organic) and silicon (inorganic). The silicon rubber (siloxane) backbone unit $\mathrm{Si}-\mathrm{O}$ has a bond length of $1.63 \AA$ and a bond angle of $130^{\circ}$ which make it more flexible compare to C-C (bond length of $1.54 \AA$ and a bond angle of $112^{\circ}$ ) backbone unit. Silicone hoses, made of mainly organo-silicon polymer with a silicon-oxygen framework whose simplest fundamental unit is $\left(\mathrm{R}_{2} \mathrm{SiO}\right) \mathrm{n}$ and are characterized by significant properties such as insusceptibility to cracks, durability, offer good resistance to extreme temperature, a facile operation process, bacteria-resistance and excellent resistance to weathering and is not a hazard to the environment [1]. SR hose are stable bellow the melting temperature, almost all of which are at around $150^{\circ} \mathrm{C}$. Therefore, silicon rubbers are often denoted as "non-degradable or bio resistant". This is of course not true, since all polymers, synthetic as well as native, are degraded when exposed to nature.

In spite of these there are reports from all over the world regarding the degradation of silicone rubbers [2-19], in various environments for its main structural modifications seen in damaged structure are changes in molecular weight distribution (due to main-chain scission, crosslinking, and end-linking) and production of 
volatile degradation product. Zhu, et al. [6] studied the surface degradation of silicone rubber exposed to corona discharge. Gustavsson, et al. [14] reported the results of aging of silicone rubber under ac or dc voltages in a coastal environment. A review on the effects and degradation process of silicones in the environment can be found in Graiver, et al. [15]. Tan, et al. [16] reported the degradation of elastomeric gasket materials in a simulated fuel cell environment. Despite these possible disadvantages for silicon rubber, limited number of publications concerning degradation of silicon rubber have been made from both academic and industrial institutions. However, all silicones are man made; no naturally occurring silicone has ever been convincingly demonstrated. Silicones, with their silicon-oxygen backbone, are structurally very far from other macromolecules. It was found that the decrease of Si-O content indicates that the major damage of the silicone rubber is caused by surrounding environmental conditions and the mass loss ratio of the silicone rubber increase due to volatile substances generated by the degradation of silicone rubber in the high vacuum environment [2].

However, up to date, the research of damage mechanism for SR hose occurred by industrial application is still on the very beginning stage.

Although there are a substantial literatures concerning the degradation of silicone rubber have been extensively studied, there are no investigation work have done regarding the damage silicone rubber hose that may occur when they are contacted to beverage, drinking products and hose washing chemicals in a processing factory.

The aim of the present study was to investigate the degree of degradation and the mechanism for the damaged silicon rubber hoses was subjected to continuous juice load and was expose to the chemical environment.

In this paper, the chemical shift of damaged silicon rubber was studied, and the damage mechanism caused by the hose washing chemicals was primarily discussed. The material characterization method was performed to assess the structural changes of the SR hose before and after exposure to the chemical environment.

\section{Materials and Analysis Procedure}

\subsection{Materials}

We have collected the damaged silicon hoses attached to UHT sterilizer (sterilization of juice at $110^{\circ} \mathrm{C}-135^{\circ} \mathrm{C}$ before packaging) and examined them for chemical changes. Figure 1 shows the flow sheet of the SR hose cleaning process in juice factory. We also analyzed the original new SR hose $(\mathrm{N})$ for comparing the chemical structural difference with cracked (P1) and non-defect
(P2) surface of the damaged one. All chemicals and standards were of the highest purity grade. MilliQ water (resistivity 18.2 M $\Omega$ ) was used during the experiments. Orange and apple juice were collected from affected juice factory. Other reagents, including $\mathrm{HNO}_{3}$ (Tama pure) and $\mathrm{NaOH}$ were analytical reagent grade and were purchased from Kanto Chemical.

\subsection{Analysis of new SR hoses}

The damage formation was studied in laboratory on new SR hose surface at temperatures at $110^{\circ} \mathrm{C}$ and $25^{\circ} \mathrm{C}$ Figure 1. The juice flow and hose washing-chemicals were controlled by peristaltic pump. The reservoir (flat bottom volumetric flux) of this system was filled ones a day with juice and cleaned up the SR hose by washing chemical every after 24 h, following the steps of Figure 1 for one month. We have collected the hose washing chemicals to measure the Si concentration that leached from SR hose backbone.

\subsection{Silicon Hose Characterization}

\subsubsection{System Stereomicroscope}

Inner surface picture of new and damage silicon hose was taken by System Stereomicroscope (SMZ 1000)

\subsubsection{FE-SEM (Field Emission Scanning Electron Microscope)/EDS (Energy Dispersive Spectroscopy)}

The surface characteristics were analyzed using FE-SEM (JEOL, FE-SEM 6700F). The elemental composition (Si, $\mathrm{O}, \mathrm{C}$ and $\mathrm{Na}$ ) was determined with an energy dispersive $\mathrm{X}$-ray spectrometer (EDS, JED-2200). The acceleration voltage of $15 \mathrm{kV}$ and a beam current of $6 \times 10^{-8} \mathrm{~A}$ were used in the SEM-EDS-analyses. The sample distance was $15 \mathrm{~mm}$ and the analyses were carried out with $\times 200$ $-\times 10000$ magnification.

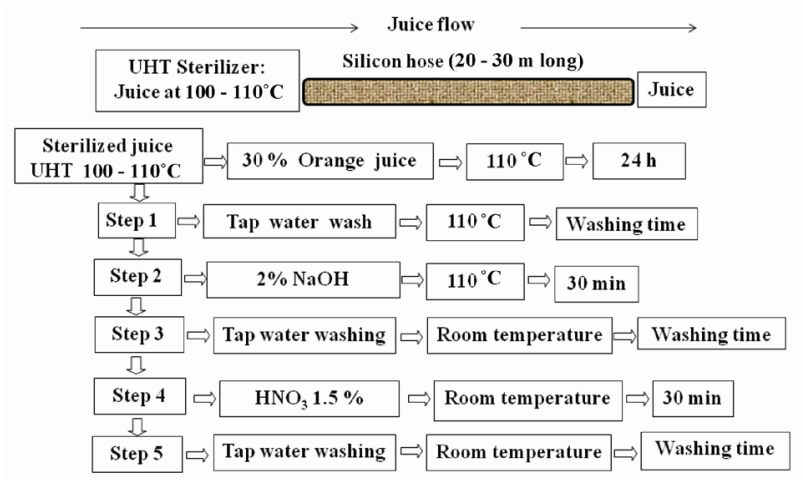

Figure 1. Flow chart for silicon rubber (SR) hose cleaning system in juice factory. 


\subsubsection{Wavelength Dispersive $X$-Ray Fluorescence (WD-XRF)}

We measured the weight percentage of elements and their atomic concentration of new and damaged hose by using WD-XRF-PW 2404R, Philips machine in University of Toyama, Japan.

\subsubsection{Carbon Hydrogen Nitrogen Sulfur (CHNS) Analyzer}

The weight percentage of carbon (C) and hydrogen (H) were determined by the CHNS analyzer (VarioMICROcube TYU).

\subsubsection{UV-Vis Spectrometer 1600}

Leached Silicon concentration in washing chemicals was measured at $\lambda=380 \mathrm{~nm}$ with a Shimadzu UV-1600 spectrophotometer.

\subsubsection{Solubility Test}

Only P1 was dissolved in DMF (fine particles were found inside DMF solution) where as P2 and new silicon hose $(\mathrm{N})$ was not dissolved in DMF solvent.

\section{Results and Discussions}

We developed a plan to research the brittleness in silicon hoses; first, we characterized the damaged hoses collected from Juice Company using different analysis methods and confirmed any chemical differences between these hoses and new ones. Then, to clarify any chemical and physical changes to the hoses that took place during one month use in juice factory, a laboratory study was undertaken to investigate the damage of the silicon hoses.

\subsection{Characterization of Industrial Damaged Silicon Hose}

\subsubsection{Structure of New $(\mathrm{N})$ and Industrial Damaged (P1, P2) Silicon Hose}

Silicon hose is classified as an organo-silicon compounding system, composed of base (base-7100), polyester threads (non-phthalic acid) and special PET (poly ethylene terephtalate) resin catalyst, crosslinking agent etc. The new test silicon hose can be used in a wide range of temperature of $-30^{\circ} \mathrm{C}$ to $150^{\circ} \mathrm{C}$.

Figure 2(a) shows the repeat unit (n) of silicon rubber. When " $n$ " is small (low molecular weight), the polymer exhibits low physical properties, and in some cases, it may be a liquid. As " $\mathrm{n}$ " increases (molecular weight increases), the polymer's physical properties are improved. Silicone rubber polymer chains are generally between 3,000 and 10,000 monomer units in length. The test new silicon hose samples $(\mathrm{N})$ has a repeat unit of 900 - 1000 monomer unit in length. Figure 2(b) represents the new silicon hose structure, the first inner surface is the silicon rubber phase, which is covered with polyester thread, and finally the upper surface is made of silicon rubber. New hose $(\mathrm{N})$ picture shows the transparency between inner and outer surface in Figure 2(c). In Figure 2(e), similar round-shaped spot were found on the damaged surface of the SR hose and one hole was found for the entire round-shaped damaged spot.

\subsubsection{Schematic Diagram of the Damage Area inside Used Hose}

In Figure 2(d), the damage hose had defects appearing inside the affected areas (P1) as not transparent where as the unaffected areas (P2) of damage hose is transparent. According to the Figure 2(d) some chemical deformation occurred in damaged part (P1) inside the used hose. Figure 2(e) shows the location of the cracking areas inside the damaged hose. Figure 2(e) also shows the damage characterization as silicon rubber become yellow from milky white color after using it in juice factory and got 4 spot inside (spot diameters are $5 \mathrm{~mm}, 8 \mathrm{~mm}, 12$ $\mathrm{mm}, 16 \mathrm{~mm}$ ) in $15 \mathrm{~cm}$ long damaged hose. The shape of the affected area is round type and the fragility of the spot contains cracking line in the middle area of the spot. Polyester threads became hard, brittle and black from white color.

\subsubsection{Determination the Chemical Changes in Damaged SR Hose by FE-SEM/EDS after Using it in Juice Factory}

The aim of the FE-SEM/EDS analysis is to determine the chemical changes that occurred inside the SR hose after

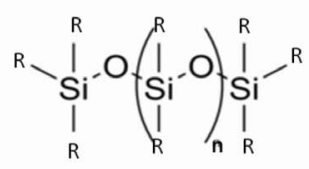

(a)

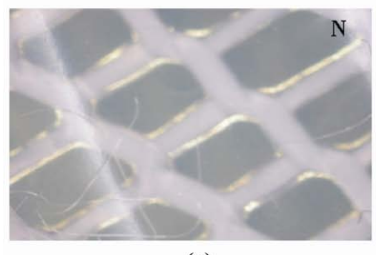

(c)

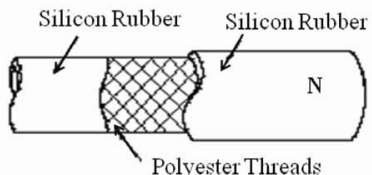

(b)

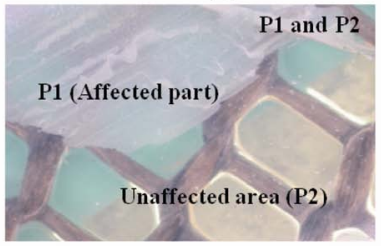

(d)

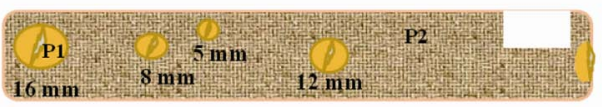

(e)

Figure 2. (a) Repeat unit of SR; (b) hose structure (N); Stereomicroscopic image of inner surface of (c) new and (d) damaged hose; (e) cracking shape on the damaged surface. 
exposure to fruits juice and washing chemicals at high temperature. FE-SEM mapping was used to visually observe the degradation of the fluid-contacted surface of the damaged hose. Figure 3 shows the surface photograph of new SR hose Figures 3(a) and 3(b); unaffected areas of damaged SR hose Figures 3(c) and 3(d) and affected areas of damaged hose Figures 3(e) and 3(f). The results clearly shows that surface conditions were changed over time from initially smooth Figure 3(a) to first cracking line Figure 3(c) and to cracked surface Figure 3(e). Specially, after 5 weeks of exposure to the fluid environment (juice and washing chemicals), small cracks appeared on the surface of new hose Figures 2(e) and 3(c). The crack size increased significantly with increasing exposure time. Figures 3(d) and 3(f) showed the surface image with the degreasing concentration of Si in damaged areas.

From Figure 4, it could be seen that the degradation
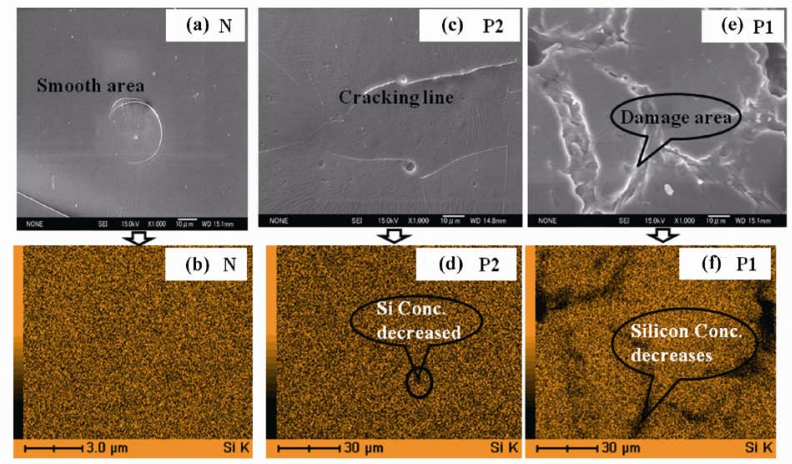

Figures 3. (a) Smooth new hose surface: N, (c) non damaged area of used hose: P2, (e) cracked area of used hose: P1; (b) SEM mapping for silicon concentration of (b) N, (d) $P 2$ and (f) P1 hose surface.
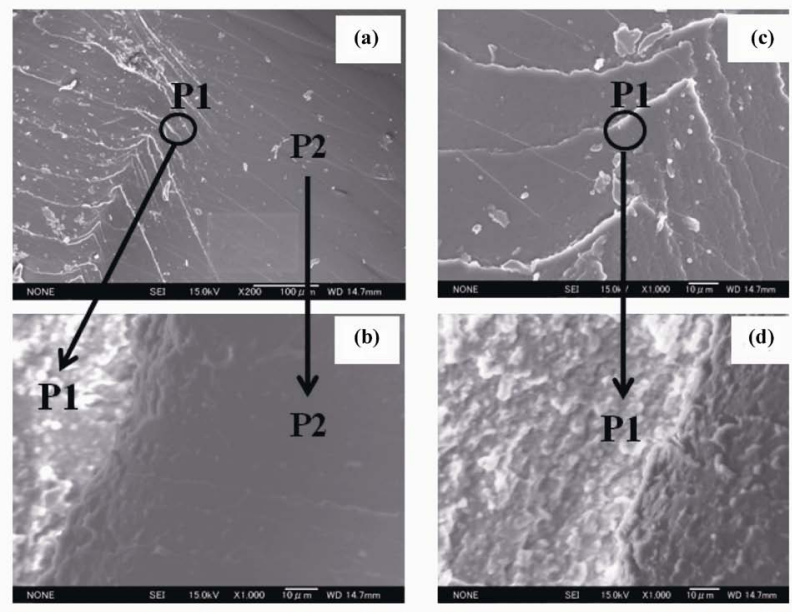

Figure 4. (a) and (b): Significant changes in the P1 surface occurred gradually from P2 to P1 during fluid exposure; (c) and (d): SEM image of damaged area (P1). degree gradually increased from unaffected surface (P2) to cracked surface (P1) in damaged hose.

Figure 5 represented the FE-SEM mapping of the cross section picture of new and damaged hose. There are three parts in each cross section; 1) outer section, 2) thread line and 3) inner section. The outer and unexposed inner surfaces for new hose showed smooth surface Figure 5(a). The unaffected outer surfaces of damaged hoses (P2-2) are also smooth and there were no cracking found on the surfaces. The fluid contacted inner side (P2-1) was rough and little cracks were found Figure 5(d) on the surface. Figure 5(e) (P1) shows the evi- dence of crack, where considerable big and small degra- dation were observed.

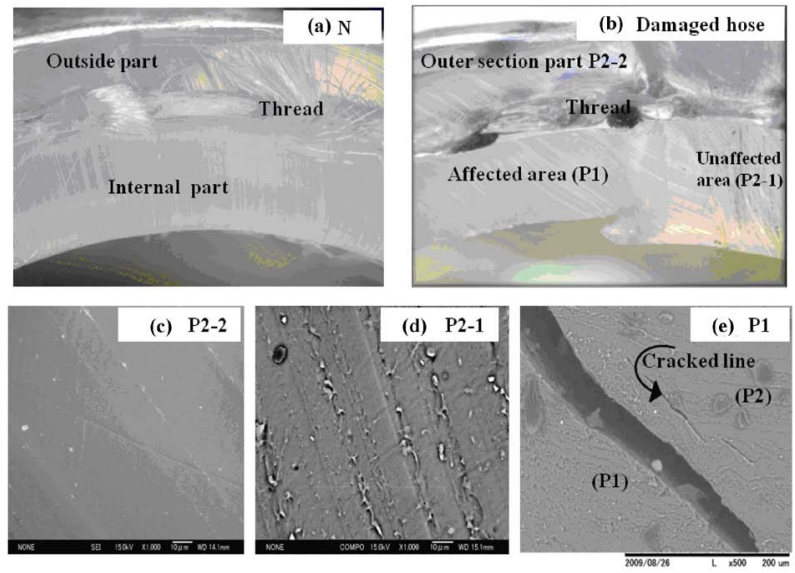

Figure 5. Cross Section of new and damaged hose; (a) New SR hose; (b) Damaged hose (P1 and P2); (c) Damaged hose (outer section P2); (d) Damaged hose (inner section P2); (e) Damaged hose (affected part P1).
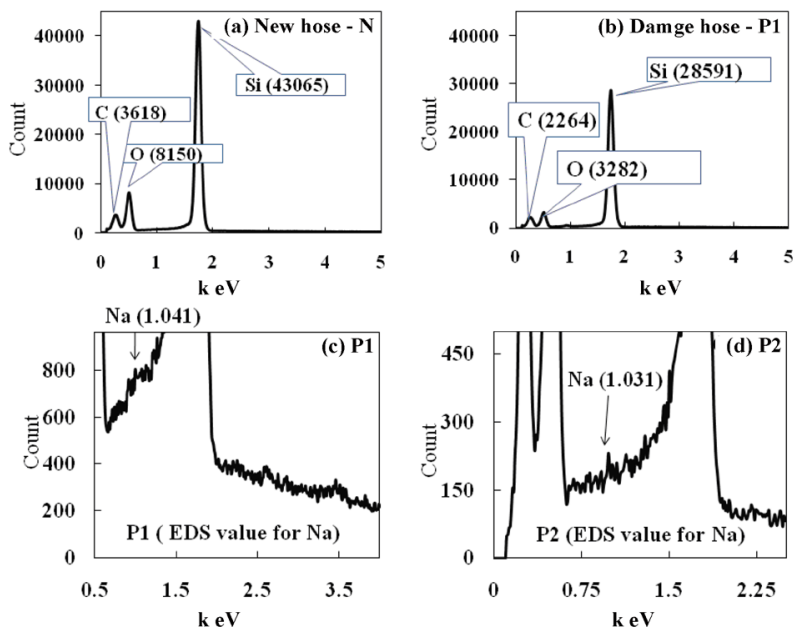

Figure 6. EDS elemental peaks for (a) new (N1) and (b) damage hose (P1); (c) Na-peak (Na: $1.041 \mathrm{keV}$, newly inserted) inside the damage area (P1 and P2). 
Table 1. Elemental compositions of new and industrial damaged silicon hose.

\begin{tabular}{ccccc}
\hline Elements & Base (At. Conc. \%) & $\begin{array}{c}\text { New Hose (N) } \\
\text { (At. Conc. \%) }\end{array}$ & $\begin{array}{c}\text { Unaffected surface (P2) } \\
\text { (At. Conc. \%) }\end{array}$ & $\begin{array}{c}\text { Cracked surface } \\
\text { (P1) (At. Conc. \%) }\end{array}$ \\
\hline Si & 21.98 & 20.19 & 18.39 & $16.31(\mathrm{~b})-17.93(\mathrm{c})$ \\
$\mathbf{O}$ & 29.94 & 29.38 & 28.96 & $23.08(\mathrm{~b})-23.97(\mathrm{c})$ \\
$\mathbf{N a}$ & 0 & 0 & 0.01 & 0.07 (b) -0.19 (c) \\
\hline
\end{tabular}

\subsubsection{Detection of Na inside Damaged Hose}

In order to get more information about the damage mechanism and elemental changes on the chemical contacted surface of SR hose was investigated by EDS analysis. Figure 6 showed EDS surveyed spectra for SR hose before and after one month exposure to juice and washing chemicals at $100^{\circ} \mathrm{C}-110^{\circ} \mathrm{C}$. The spectra revealed the presence of silicon $(\mathrm{Si})$, oxygen $(\mathrm{O})$ and carbon $(\mathrm{C})$ Figures 6(a) and 6(b) and small amount of so- dium (Na) in damaged hose Figures 6(c) and 6(d). From EDS data, the atomic concentrations of $\mathrm{Si}, \mathrm{O}$ and $\mathrm{C}$ decreased significantly for damaged hose Figure 6(b) and estimated to be Si: $62.39 \%$, O: $40.26 \%$ and C: $62.57 \%$ compare to new hose. The EDS peak of Na for both P1 and P2 was observed at $1.041 \mathrm{keV}$. This fact would indicate that $\mathrm{Na}$, which was formed during the hose washing process with $\mathrm{NaOH}$ followed by Na-sili- cate formation. According to elemental analysis Table 1, silicon concentration was decreased in the following order: 20.19 (new hose: N) > 18.39 (non-cracked surface of damaged hose: P2) > 16.31 (cracked surface of dam- aged hose: P1).

The comparative study between the Figures 2(e) and 3(c) are important; indicating that the first cracking line had been started inside the surface area of P2 Figure 3(c) and the affected areas length gradually increased and turned into round shape that showed in Figure 2(e).

\subsubsection{Compare the Elemental Concentration of the New and the Damaged Hoses Using WD-XRF}

The use of WD-XRF as a multi-elemental method for the analysis of plastics has been widely described [20-23]. One of the biggest advantages of XRF is that solid materials can be analyzed without foregoing sample digestion.

The main elemental compositions of SR hose are Si, $\mathrm{O}, \mathrm{C}$ and $\mathrm{H}$ with lesser amounts of other elements. The ele- ment ( $\mathrm{Si}$, $\mathrm{O}$ and other tracer elements) compositions of damaged and new hoses were obtained by X-ray fluorescence using a Wavelength-Dispersive XRF spectrometer. Carbon $(\mathrm{C})$ and hydrogen $(\mathrm{H})$ were measured with a CHNS analyzer. Silicon (Si) concentration is less in damaged than in new hoses Table 1. As illustrated, the weight percent of silicon and oxygen was decreased and

Table 2. Compare the elements of monomer unit (Si, $\mathrm{O}$, and
Na) of new (N), analyzed (L) and damaged (P1) silicon rubber hose.

\begin{tabular}{|c|c|c|c|c|}
\hline Elements & $\begin{array}{c}\mathbf{N} \\
\mathbf{W t} \%\end{array}$ & $\begin{array}{c}\mathbf{L} \\
\mathbf{W t} \%\end{array}$ & $\begin{array}{c}\text { S } \\
W t \%\end{array}$ & $\begin{array}{c}\text { P1 } \\
\text { Wt\% }\end{array}$ \\
\hline $\mathrm{Si}$ & 48.19 & 44.62 & 43.4 & 41.14 \\
\hline $\mathrm{O}$ & 25.81 & 24.18 & 19.90 & 18.81 \\
\hline $\mathrm{Na}$ & 0 & 0.06 & 0.07 & 0.1 \\
\hline
\end{tabular}

Table 3. Determine the silicon (Si) concentration in washing chemicals.

\begin{tabular}{cccc}
\hline $\begin{array}{c}\text { Washing chemi- } \\
\text { cals/Temp }\end{array}$ & Concentration \% & pH & $\begin{array}{c}\text { Si }(\mu \mathrm{M}) \text { (wash- } \\
\text { ing chemicals) }\end{array}$ \\
\hline $\mathrm{HNO}_{3} / 25^{\circ} \mathrm{C}$ & $1.5 \%$ & 0.67 & 12.91 \\
$\mathrm{NaOH} / 90^{\circ} \mathrm{C}$ & $2 \%$ & 13.71 & 2.3 \\
$\mathrm{NaOH} / 90^{\circ} \mathrm{C}$ & $0.004 \%$ & 11.52 & 163.79 \\
\hline
\end{tabular}

sodium was increased after the degradation of the SR hose in juice factory and after the hose surface was exposed in chemicals in laboratory Table 2.

The reduction of silicon (Si) in damaged hose is not equivalent to the increasing amount of sodium $(\mathrm{Na})$ for the damaged hoses. Consequently, the sodium concentration of the damaged hose had increased, which indicates that the original structure of the SR hose had been modified by reaction with the washing chemical $(\mathrm{NaOH})$. The silicon and the oxygen concentrations had decreased in the used hose, which indicates that the Si had leached out of the hose and the hose had become brittle. This is because the main raw materials of the SR hose (siliconbase), which contains silicon, oxygen and carbon Figure 2(a). The exposed parts of the SR hose (P1 and P21 ) in fruits juice and in washing chemicals became brittle, whereas the unexposed parts (P2-2) in fluid were almost unaffected (Figure 5(c)). The silicon and oxygen concentrations were lower in the parts exposed to hot fluid $(\mathrm{N}<\mathrm{P} 2<\mathrm{P} 1)$, which also indicates the importance of temperature relative to the damage of the SR hose.

\subsubsection{Determination of Leached Silicon (Si) from Washing Chemicals by UV-Visible Spectrometer}

Leached Silicon (Si) was estimated from the washing chemicals $\left(\mathrm{NaOH}\right.$ and $\left.\mathrm{HNO}_{3}\right)$. The measured silicon concentrations from different washing chemicals at various $\mathrm{pH}$ are given in Table 3. According to Table 3, decreasing the alkali $(\mathrm{NaOH})$ concentration $(2 \%>0.004 \%)$ 
and decreasing the alkali pH $(13.70>11.52)$, increasing the Si dissolution from SR hose. The leaching also increased in acid medium (1.5\% $\mathrm{HNO}_{3}$, $\left.\mathrm{pH} 0.67\right)$.

\subsection{Possible Effect of Washing Chemicals ( $\mathrm{NaOH}$ and $\mathrm{HNO}_{3}$ ) on Exposed SR Hose}

The properties of silicon rubber come from the structure of the polymer. However, chemical attack can affect the backbone of silicon rubber during utilization and result in intensive mass loss and property degradation [24].

\subsubsection{Effect of $\mathrm{HNO}_{3}$}

The primary chemical bonds and their binding energies for the silicon rubber are $\mathrm{E} \mathrm{Si-O}\left(451 \mathrm{~kJ} \cdot \mathrm{mol}^{-1}\right)$, E Si-C $\left(368 \mathrm{~kJ} \cdot \mathrm{mol}^{-1}\right)$ and $\mathrm{E} \mathrm{C}-\mathrm{H}\left(410 \mathrm{~kJ} \cdot \mathrm{mol}^{-1}\right)$ respectively. In the silicon rubber, the binding energy of Si-O bonds (siloxane bond) in the main chains is a little higher, but the negativities are different between $\mathrm{Si}$ and $\mathrm{O}$ and the difference could reach 1.7. The Si-O bonds possess $50 \%$ iconicity, and under the acidic medium, the $\mathrm{O}$ atoms in the Si-O bonds may react with $\mathrm{H}^{+}$firstly and then forms cationic radicals, which would accelerate the rupture

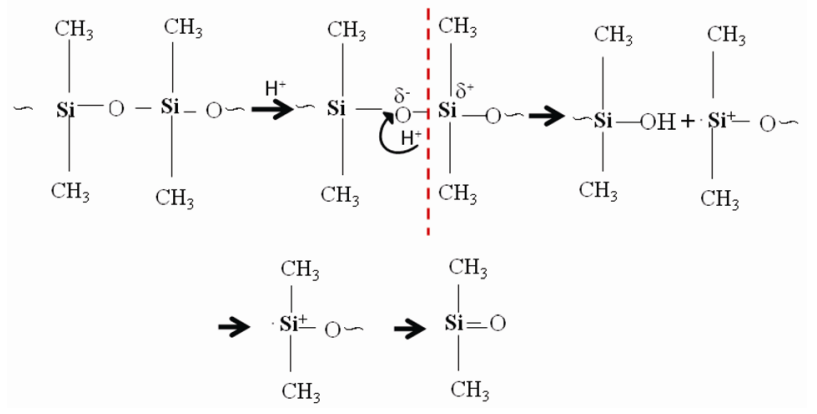

(a)

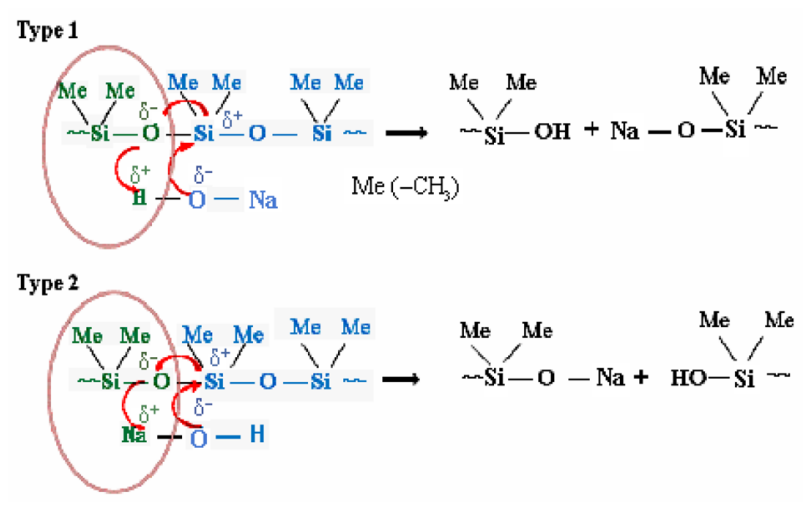

(b)

Figure 7. (a) Probable degradation mechanism of SR hose occurred by $\mathrm{HNO}_{3}$; (b) Probable degradation by $\mathrm{NaOH}$. forms cationic radicals, which would accelerate the rupture of the macromolecule chains of the silicon rubber ture of the macromolecule chains of the silicon rubber Figure 7(a) [5]. The above degradation process can be summarized as Figure 7(a).

\subsubsection{Effect of $\mathrm{NaOH}$}

Due to the highly ionic character of the siloxane bond this polymer is sensitive to alkaline attack. Figure $\mathbf{7 ( b )}$ represent the possible degradation pathway for the rapture of silicon-oxygen bonds. The presence of $\mathrm{NaOH}$ gives the following reactions scheme [25]: $>\mathrm{SiOSi}<+$ $\mathrm{NaOH} \rightarrow->\mathrm{SiOH}+\mathrm{NaOSi}<-$ Figure 7(b). The dissolution of silicone basically depends on the breakage of $\mathrm{Si}-\mathrm{O}$ bonds of SR hose by $\mathrm{NaOH}$ and, thereby, the important factors should be considered to facilitate the degradation, i.e. concentration of $\mathrm{NaOH}$ in the solvent [26].

According to the results of the observation of chemical effect on the new hose surface, the Na concentration was higher when $\mathrm{NaOH}$ contacted the inner surface $\left(100^{\circ} \mathrm{C}\right.$ $120^{\circ} \mathrm{C}$, average UTH temperature) compare to outer surface of the same hose where fluid was not contacted and under identical conditions. Due to the highly ionic character of the siloxane bond this polymer is sensitive to alkaline attack. Figure 7(b) represent the possible degradation pathway for the rapture of silicon-oxygen bonds. The presence of $\mathrm{NaOH}$ gives the following reactions scheme [25]: $>$ SiOSi $<+\mathrm{NaOH} \rightarrow->\mathrm{SiOH}+\mathrm{NaOSi}$ $<-$ Figure 7(b). The dissolution of silicone basically depends on the breakage of Si-O bonds of silicon rubber hose by $\mathrm{NaOH}$ and, thereby, the important factors should be considered to facilitate the degradation, i.e. concentration of $\mathrm{NaOH}$ in the solvent [26]. According to the results of the observation of chemical effect on the new hose surface, the $\mathrm{Na}$ concentration was higher when $\mathrm{NaOH}$ contacted the inner surface $\left(100^{\circ} \mathrm{C}-120^{\circ} \mathrm{C}\right.$, average UTH temperature) than the outer surface of the same hose where fluid not contacted and under identical conditions. $\delta$

\section{Conclusions}

The following statements are based on the results:

- According to Fe-SEM/EDS and elemental analysis, silicon ( $\mathrm{Si}$ ) and oxygen (O) concentration was decreased in the following order: new hose $>\mathrm{NaOH}$ treatments hose Surfaces $>$ cracked surface of damaged hose (collected from juice company) which reveled that Si was leached out from SR back bone.

- The EDS peak of Na appeared at the peak position of $1.04 \mathrm{keV}$ in damaged hose and no peak due to $\mathrm{Na}$ appeared for new hose.

- The atomic concentration of Na for both P2 and P1 
surfaces was estimated to be 0.009 and $0.07(b)$ 0.184 (c) respectively. These facts would indicate that sodium, which was inserted by chemical reaction during the hose washing process with $\mathrm{NaOH}$ followed, remained inside the silicon backbone, therefore, incorporation of $\mathrm{Na}$ into the P1 and P2 surface was clear.

- UV-Visible spectroscopy result shows the presence of leached $\mathrm{Si}$ in hose washing chemicals $(2 \% \mathrm{NaOH}, 1.5$ $\mathrm{HNO}_{3}$ ).

Therefore, silicon hose were degraded, judged by silicon loss and $\mathrm{Na}$ insertion into silicon rubber backbone occurred by hose washing process

\section{Acknowledgements}

This research was carried out with the financial support of Scientific Research from the Ministry of Education, Culture, Sports, Science and Technology of Japan under grant numbers 16681004 and 19310007 . We thank our laboratory M. Sc. student Kyohei Matsumoto for his technical assistance.

\section{References}

[1] S. J. Clarson and J. A. Semlyen, "Siloxane Polymers," PTR-Prentice Hall, Englewood Cliffs, 1993.

[2] C. J. Lammi and D. A. Lados, "Effects of Residual Stresses on Fatigue Crack Growth Behavior of Structural Materials: Analytical Corrections,” International Journal of Fatigue, Vol. 33, No. 7, 2011, pp. 858-867. doi:10.1016/j.ijfatigue.2011.01.019

[3] M. Schulze, T. Knori, A. Schneider and E. Gulzow, "Degradation of Sealings for PEFC Test Cells during Fuel Cell Operation,” Journal of Power Sources, Vol. 127, No. 1-2, 2004, pp. 222-229. doi:10.1016/j.jpowsour.2003.09.017

[4] B. K. Deka and T. K. Maji, "Study on the Properties of Nanocomposite based on High Density Polyethylene, Polypropylene, Polyvinyl Chloride and Wood," Composites Part A: Applied Science and Manufacturing, Vol. 42, No. 6, 2011, pp. 686-693. doi:10.1016/j.compositesa.2011.02.009

[5] L. X. Zhang, S. Y. He, Z. Xu and Q. Wei, "Damage Effects and Mechanisms of Proton Irradiation on Methyl Silicone Rubber," Material Chemistry and Physics, Vol. 83, No. 2-3, 2004, pp. 255-259. doi:10.1016/j.matchemphys.2003.09.043

[6] Y. Zhu, K. Haji, M. Otsubo and C. Honda, "Surface Degradation of Silicone Rubber Exposed to Corona Discharge," IEEE Transations on Plasma Science, Vol. 34, No. 4, 2006, pp. 1094-1098. doi:10.1109/TPS.2006.876498

[7] M. Patel, A. R. Skinner and R. S. Maxwell, "Sensitivity of Condensation Cured Polysiloxane Rubbers to Sealed and Open-to Air Thermal Ageing Regimes,” Polymer Testing, Vol. 24, No. 5, 2005, pp. 663-668. doi:10.1016/j.polymertesting.2005.03.013

[8] L. Meunier, G. Chagnon, D. Favier, L. Orgéas and P. Vacher, "Mechanical Experimental Characterisation and Numerical Modelling of an Unfilled Silicone Rubber," Polymer Testing, Vol. 27, No. 6, 2008, pp. 765-777. doi:10.1016/j.polymertesting.2008.05.011

[9] M. Ehsani, H. Borsi, E. Gockenback, G. R. Bakhshandeh and J. Morshedian, "Modified Silicone Rubber for Use as High Voltage Outdoor Insulators," Advances in Polymer Technology, Vol. 24, No. 1, 2005, pp. 51-61. doi:10.1002/adv.20027

[10] A. Ghanbari-Siahkali, S. Mitra, P. Kingshott, K. Almdal, C. Bloch and H. K. Rehmeier, "Investigation of the Hydrothermal Stability of Cross Linked Liquid Silicon Rubber (LCR),” Polymer Degradation and Stability, Vol. 90, No. 3, 2005, pp. 4711-480.

[11] A. N. Chaudhry and N. C. Billingham, "Characterization and Oxidative Degradation of a Room-Temperature Vulcanized Poly (Dimethylsiloxane) Rubber," Polymer Degradation and Stability, Vol. 73, No. 3, 2001, pp. 505-510. doi:10.1016/S0141-3910(01)00139-2

[12] B. H. Youn and C. S. Huh, "Surface Degradation of HTV Silicone Rubber and EPDM Used for Outdoor Insulators under Accelerated Ultraviolet Weathering Condition,” IEEE Transactions on Dielectrics and Electrical Insulation, Vol. 12, No. 5, 2005, pp. 1015-1024. doi:10.1109/TDEI.2005.1522194

[13] H. Liu, G. Cash, D. Birtwhistle and G. George, "Characterization of a Severely Degraded Silicone Elastomer HV Insulator-an Aid to Development of Lifetime Assessment Techniques," IEEE Transactions on Dielectrics and Electrical Insulation, Vol. 12, No. 3, 2005, pp. 478-486. doi:10.1109/TDEI.2005.1453452

[14] T. G. Gustavsson, S. M. Gubanski, H. Hillborg, S. Karlsson and U. W. Gedde, "Ageing of Silicone Rubber Materials under AC and DC Voltages in a Coastal Environment," IEEE Transaction on Dielectrics and Electrical Insulation, Vol. 8, No. 6, 2001, pp. 1029-1039. doi:10.1109/94.971462

[15] D. Graiver, K. W. Farminer and R. Narayan, "A Review of the Fate and Effects of Silicones in the Environment," Journal of Polymers and the Environment, Vol. 11, No. 4, 2003, pp. 129-136. doi:10.1023/A:1026056129717

[16] J. Tan, Y. J. Chao, J. W. Van Zee and W. K. Lee, “Degradation of Elastomeric Gasket Materials in PEM Fuel Cells,” Materials Science and Engineering A, Vol. 445446, 2007, pp. 669-675. doi:10.1016/j.msea.2006.09.098

[17] M. Di, S. He, R. Li and D.-Z. Yang, "Radiation Effect of $150^{\circ} \mathrm{keV}$ Protons on Methyl Silicone Rubber Reinforced with MQ Silicone Resin,” Nuclear Instruments and Methods in Physics Research Section B: Beam Interactions with Materials and Atoms, Vol. 248, No. 1, 2006, pp. 31-36. doi:10.1016/j.nimb.2006.02.017

[18] N. Yoshimura, S. Kumagai and S. Nishimura, "Electrical and Environmental Aging of Silicone Rubber Used in 
Outdoor Insulation," IEEE Transactions on Dielectrics and Electrical Insulation, Vol. 6, No. 5, 1999, pp. 632650. doi:10.1109/94.798120

[19] Q. Xu, M. Pang, L. Zhu, Y. Zhang and S. Feng, “Mechanical Properties of Silicone Rubber Composed of Diverse Vinyl Content Silicone Gums Blending,” Materials \& Design, Vol. 31, No. 9, 2010, pp. 4083-4087. doi:10.1016/j.matdes.2010.04.052

[20] H. Fink, U. Panne, M. Theisen, R. Niessner, T. Probst and X. Lin, "Determination of Metal Additives and Bromine in Recycled Thermoplasts from Electronic Waste by TXRF Analysis Fresenius," Journal of Analytical Chemistry, Vol. 368, 2000, pp. 235-239.

[21] U. Metz, P. Hoffmann, S. Weinbruch and H. M. Ortner, "A Comparison of X-Ray Fluorescence Spectrometric (XRF) Techniques for the Determination of Metal Traces, Especially in Plastics,” Mikrochimica Acta, Vol. 117, No. 1-2, 1994, pp. 95-108. doi:10.1007/BF01243020

[22] V. P. Martinez, F. B. Reig, J. V. Gimeno Adelantado and M. T. Doménech Carbó, "Multi-Elemental Determination of Heavy Metals using X-Ray Fluorescence after De- struction of the Polymer by Molten Sodium Hydroxide Fresenius,” Journal of Analytical Chemistry, Vol. 342, 1992, pp.586-590.

[23] M. S. Nahar and J. Zhang, "Influence of Biogeochemical Qualities of Shizuoka Water on the Degradation of PVC Shower Hose," Journal of Environmental Protection, No. 2, 2011, pp. 204-212. doi:10.4236/jep.2011.22024

[24] I. Stevenson, L. David, C. Gauthier, L. Arambourg, J. Davenas and G. Vigier, "Influence of $\mathrm{SiO}_{2}$ Fillers on the Irradiation Ageing of Silicone Rubbers," Polymer, Vol. 42, No. 22, 2001, pp. 9287-9292. doi:10.1016/S0032-3861(01)00470-0

[25] F. G. A. Stone and W. A. G. Graham, "Inorganic Polymers,” Academic Press, New York, 1992.

[26] W. Huang, Y. Ikeda and A. Oku, “Recovery of Monomers and Fillers from High-Temperature-Vulcanized Silicone Rubbers-Combined Effects of Solvent, Base and Fillers,” Polymer, Vol. 43, No. 26, 2002, pp. 7295-7300. doi:10.1016/S0032-3861(02)00713-9 